weight was self-reported. Among the complete 139 twin pairs, the mean difference in intra-pair birth weight difference was -24 gram ( $95 \%$ confidence interval; -863 gram to +815 gram). Although, the mean differences between self-reported and measured birth weight/intra-pair birth weight difference is small (6.2 gram), the confidence intervals are very wide, and reflect that there are considerable discrepancies between the two measurements of birth weights. We suggest that validated birth characteristics should be used for this type of study.

\section{References}

Bland, J. M., \& Altman, D. G. (1986). Statistical methods for assessing agreement between two methods of clinical measurement. Lancet, I, 307-310.
Brix, T. H., Kyvik, K. O., \& Hegedüs, L. (2000). Low birth weight is not associated with clinically overt thyroid disease: A population based twin case-control study. Clinical Endocrinology, 53, 17I-176.

Leon, D. A. (200I). The foetal origins of adult disease: Interpreting the evidence from twin studies. Twin Research, 4, 321-326.

Roseboom, T. J., \& Lambalk, C. B. (200I). The fetal origins hypothesis. Twin Research, 4, 3.

\title{
Birthweight in Dizygotic Twins
}

\author{
William H. James \\ The Galton Laboratory, University College of London, UK
}

Loos et al. (2001) reported that among a large sample $(n=1929)$ of Dutch dizygotic (DZ) twin pairs, mean length of gestation in MF pairs is similar to that in FF pairs, and significantly longer than in MM pairs. Mean birthweight of girls from MF pairs was similar to that of girls in FF pairs, but boys from MF pairs were significantly heavier than boys from MM pairs. These authors concluded that "these data show that in unlikesex pairs, it is the girl that prolongs gestation for her brother". I responded (James, 2002) with the suggestion that differences in birthweight are consequent on competition for nutrient, and that males, being programmed to grow faster, are more successful in that competition. I acknowledged that my interpretation "would carry the expectation that females in MF pregnancies should weigh less than females in FF pregnancies" (a feature which was not evident in the data of Loos et al., 2001). Here I draw attention to some prior data which confirm that suggestion.

Orlebeke et al. (1993) reported on a larger sample of Belgian twins $(n=2277 \mathrm{DZ}$ pairs $)$. In this sample,

Table 1

Mean Birthweights (Grams) of Dizygotic Twin Members by Sex (Data of Orlebeke et al., 1993)

\begin{tabular}{lccc}
\hline & \multicolumn{3}{c}{ Sex Combination of Pair } \\
& $\mathrm{MM}(n=651)$ & $\mathrm{MF}(n=542)$ and FM $(n=490)$ & $\mathrm{FF}(n=594)$ \\
\hline Male & 2600 & 2622 & 2510 \\
Female & & 2484 & 2510 \\
\hline
\end{tabular}

boys from MF pairs weighed slightly more than those from MM pairs: and girls from MF pairs weighed slightly less than those from FF pairs. The mean birthweights of the male and female twin members are given here (see Table 1). This evidence seems to favour the suggestion that the availability of, and competition for, nutrient may have influenced the birthweights of dizygotic twins in the various categories of sex combination.

Bulmer (1970) wrote that "there can be no doubt that a large part of the reduction in the birth weight in multiple births is due to some factor other than shorter length of gestation". He concluded (p. 52) that the factor is probably an insufficient blood supply to the uterus. In other words, there is competition for nutrient among the occupants of the uterus. The notion that, within a litter, large litter-members grow large at the expense of small ones, has also been suggested in respect not only of man, but of other mammalian species, namely, the sheep and the rabbit (Beatty, 1956).

\section{References}

Beatty, R.A. (1956). Relation between genetic constitution of an offspring and weight of its litter-mates. Nature, I 78, 48.

Bulmer, M. G. (1970). The biology of twinning in man (p. 48). Oxford: Clarendon Press.

James, W. H. (2002). Gestation and birthweight in dizygotic twins. Lancet, 359 , $17 \mid-172$.

Loos, R. J. F., Derom, C., Eeckles, R., Derom, R., \& Vlietinck, R. (200I). Length of gestation and birthweight in dizygotic twins. Lancet, 358, 560-56I.

Orlebeke, J. F., van Baal, C. G. M., Boomsma, D. I., \& Neeleman, D. (1993). Birth weight in opposite sex twins as compared to same sex dizygotic twins. European Journal of Obstetrics \& Gynecology and Reproductive Biology, 50, 95-98. 